\title{
2015—another banner year for biotech
}

\section{Walter Yang}

Excluding partnership monies, biotechs raised $\$ 110$ billion in 2015, more than double 2014's second-largest total of $\$ 54.9$ billion. Follow-on offerings reached new heights of $\$ 29.7$ billion, and debt accounted for $\$ 52.7$ billion, driven by a handful of large caps, including a $\$ 10$ billion

\section{Stock market performance}

The BioCentury 100 gained $5 \%$ on the year, while the NASDAQ Biotech index jumped $11 \%$.

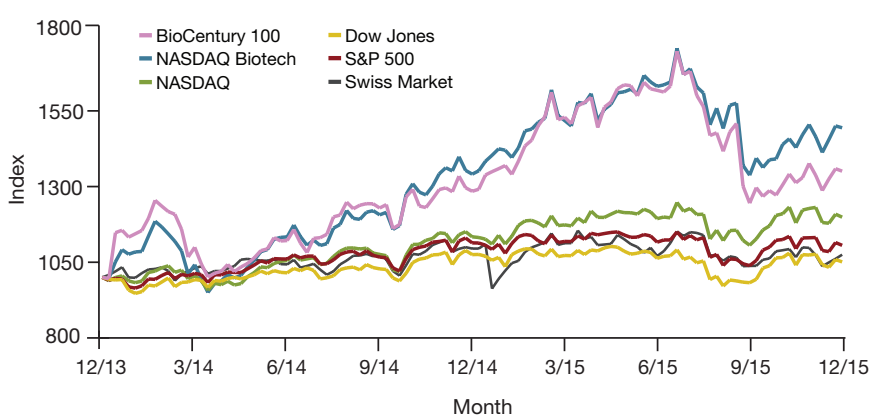

Global biotech initial public offerings

83 companies raised $\$ 8$ billion via IPOs, down from 116 (\$9.1 billion) in 2014.

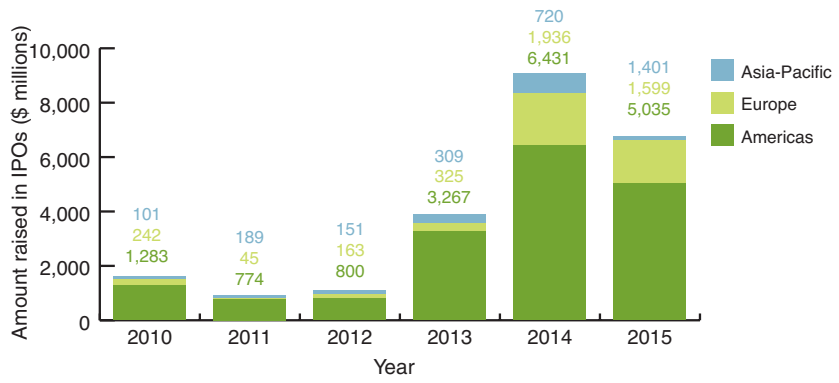

\begin{tabular}{lcccccc} 
& 2010 & 2011 & 2012 & 2013 & 2014 & 2015 \\
\hline Americas & 18 & 11 & 12 & 42 & 75 & 49 \\
Europe & 10 & 4 & 7 & 9 & 32 & 25 \\
Asia-Pacific & 5 & 9 & 6 & 9 & 9 & 9 \\
\hline
\end{tabular}

Table indicates number of IPOs. Source: BCIQ: BioCentury Online Intelligence

\section{Global biotech venture capital investment}

Private biotechs raised $\$ 12.2$ billion, up 32\% from \$9.2 billion in 2014 .

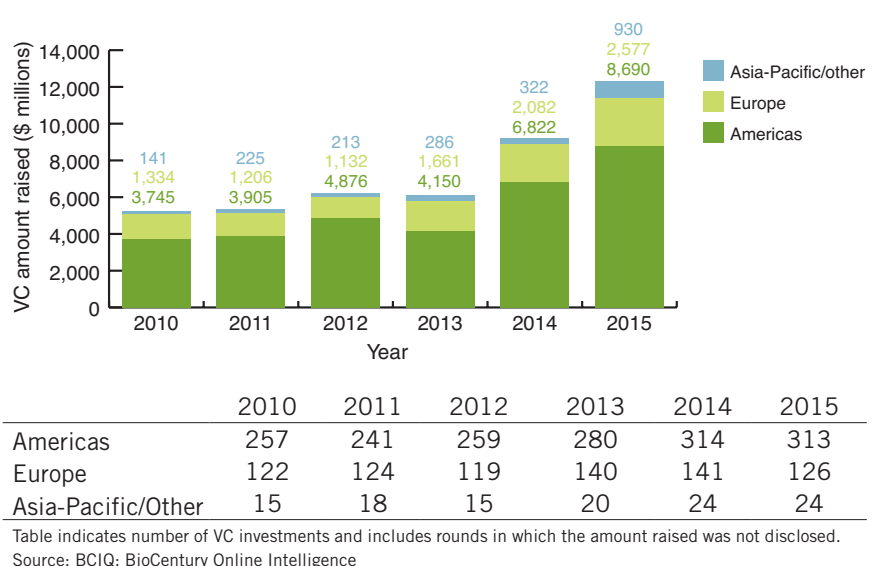

note by Gilead. Initial public offerings were $\$ 8$ billion, down from 2014's $\$ 9$ billion high but ahead of the $\$ 3.3$ billion 5 -year average. Private financings reached a record $\$ 12.2$ billion, led by a $\$ 450$ million round by Moderna.

\section{Global biotech industry financing}

Excluding partnerships, biotechs raised $\$ 110$ billion, double 2014's $\$ 54.9$ billion.

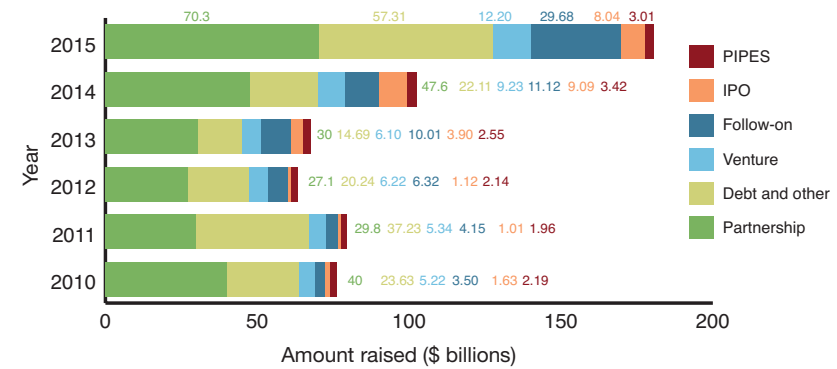

Source: $\mathrm{BCIQ}$ : BioCentury Online Intelligence.

\section{Notable 2015 deals}

\begin{tabular}{|c|c|c|c|}
\hline IPOs & & & \\
\hline Company (lead underwriters) & $\begin{array}{l}\text { Amount raised } \\
\text { (\$ millions) }\end{array}$ & $\begin{array}{l}\text { Change in } \\
\text { stock price } \\
\text { since offer }\end{array}$ & $\begin{array}{c}\text { Date } \\
\text { completed }\end{array}$ \\
\hline Inovalon (Goldman Sachs, Morgan Stanley, Citigroup) & 685 & $-37 \%$ & $11-\mathrm{Feb}$ \\
\hline $\begin{array}{l}\text { 3SBio (Morgan Stanley, Goldman Sachs, Citic Securities, } \\
\text { China International Capital) }\end{array}$ & 569 & $20 \%$ & 10-Jun \\
\hline Axovant (Jefferies, Evercore, RBC Capital) & 362 & $20 \%$ & 10-Jun \\
\hline Shanghai Haohai (UBS) & 305 & $-14 \%$ & 23-Apr \\
\hline $\begin{array}{l}\text { NantKwest (BofA Merrill Lynch, Citigroup, Jefferies, Piper } \\
\text { Jaffray) }\end{array}$ & 238 & $-31 \%$ & 28-Jul \\
\hline \multicolumn{4}{|l|}{ Venture capital } \\
\hline Company (lead investors) & $\begin{array}{l}\text { Amount raised } \\
\text { (\$ millions) }\end{array}$ & $\begin{array}{l}\text { Round } \\
\text { number }\end{array}$ & Date closed \\
\hline Moderna Therapeutics ${ }^{2}$ & 450 & ND & 6-Jan \\
\hline Immunocore ${ }^{2}$ & 320 & 1 & 16-Jul \\
\hline Pharmaron (CITIC M\&A Fund; Legend Capital) & 280 & ND & 11-Dec \\
\hline Denali Therapeutics ${ }^{2}$ & 217 & 1 & 14-May \\
\hline Adaptive Biotechnologies (Matrix Capital) & 195 & 6 & 6-May \\
\hline \multicolumn{4}{|l|}{ Mergers and acquisitions } \\
\hline Target & Acquirer & $\begin{array}{c}\text { Value } 3,4 \\
\text { (\$ millions) }\end{array}$ & $\begin{array}{c}\text { Date } \\
\text { announced }\end{array}$ \\
\hline Allergan 5 & Pfizer & $\$ 160,000$ & 29-Oct \\
\hline Pharmacyclics & AbbVie & $\$ 21,000$ & 4-Mar \\
\hline Salix & Valeant & $\$ 11,400$ & 23-Feb \\
\hline Synageva & Alexion & $\$ 8,788$ & 6-May \\
\hline Receptos & Celgene & $\$ 7,321$ & 14-Jul \\
\hline
\end{tabular}

\begin{tabular}{|c|c|c|c|}
\hline \multicolumn{4}{|c|}{ Licensing/collaboration } \\
\hline Researcher & Partner & $\begin{array}{c}\text { Value }^{4} \\
\text { (\$ millions) }\end{array}$ & Deal description \\
\hline $\begin{array}{l}\text { Hanmi } \\
\text { Pharmaceutical }\end{array}$ & Sanofi & 4,341 & $\begin{array}{l}\text { Exclusive rights to develop and commercialize long- } \\
\text { acting diabetes compounds }\end{array}$ \\
\hline $\begin{array}{l}\text { Ionis } \\
\text { Pharmaceuticals }\end{array}$ & AstraZeneca & 4,065 & $\begin{array}{l}\text { Antisense therapeutics against undisclosed targets for } \\
\text { cardiovascular, metabolic and renal diseases }\end{array}$ \\
\hline Regeneron & Sanofi & 2,665 & $\begin{array}{l}\text { Co-develop immuno-oncology candidates, including } \\
\text { PD-1 inhibitor REGN2810, and a pipeline of preclini- } \\
\text { cal mAbs and bispecific antibodies }\end{array}$ \\
\hline $\begin{array}{l}\text { CRISPR } \\
\text { Therapeutics }\end{array}$ & Vertex & 2,625 & Discover and develop treatments using CRISPRs \\
\hline uniQure & $\begin{array}{l}\text { Bristol-Myers } \\
\text { Squibb }\end{array}$ & 2,357 & $\begin{array}{l}\text { Exclusive access to uniQure's gene therapy platform } \\
\text { for multiple disease targets }\end{array}$ \\
\hline
\end{tabular}

${ }^{1}$ As of Dec, 31, 2015. ${ }^{2}$ Lead investors not disclosed. 3 Value includes milestones. 4 Value at completion if deal closed in 2015. ${ }^{5}$ Proposed enterprise deal value. ND, not determined.

Source: $B C I Q$ : BioCentury Online Intelligence 